(article published in the Journal of the British Society for Phenomenology. Vol. 34/2 (May 2003),

pp. 168-182)

\title{
The Time of Images and Images of Time: Lévinas and Sartre
}

"Beware that you do not lose the substance by grasping at the shadow." (Aesop, fl c. 550 BC, "The Dog and the Shadow")

In Time and the Other, Lévinas breaks with his typical reticence concerning Sartre's philosophy, offering the following brief yet pointed criticism:

There is some sort of angelical present in Sartre's philosophy. The whole weight of existence being thrown back onto the past, the freedom of the present is already situated above matter. In recognizing the whole weight of matter in the present itself, and in its emerging freedom, we want both to recognize material life and its triumph over the anonymity of existing, and the tragic finality to which it is bound by its very freedom. ${ }^{1}$

Proffered here is a striking indictment of Sartre's philosophy as evasion and escapism. It is as if Sartre's subject, consciousness as pour-soi, were always the angelos, the 'messenger,' and yet, at the same time, as if it were still utterly distinct from the 'message,' and therefore always indifferent toward it. Continuing the metaphor, what would then be the 'message' which Sartre's consciousness evades? The sense of its own 'being-in-time,' that is, its temporality. As a counterpoint to Sartre's view, Lévinas places emphasis, not just on sensation (which should come as no surprise to anyone who has read Husserl's Lectures on the Internal Consciousness of Time) but on the materiality of sensation. According to this passage, the materiality of sensation is crucial for temporality and in particular for the phenomenological significance of the present.

In this relatively early text from his corpus then, one finds evidence of a disjunction on Lévinas's part of his philosophy from Sartre's particular brand of existentialism. Clearly, this cleft does not arise out of questions concerning ethics and otherness, but already emerges when Lévinas brings under consideration some of the elementary phenomenological issues whose introduction into French philosophy Sartre had so crucially fostered.

In this paper, I will argue that Lévinas's insistence on the import of the matter and materiality of sensation for temporality and 'the present' is to be situated with respect to his phenomenological descriptions of the image, as found in "Reality and its Shadow" and the section on "Exoticism" in Existence and Existents. There, Lévinas's account of the image in many ways runs parallel to, if not explicitly draws upon Sartre's own account of the image, while at the same time making certain new moves of its own. Thus I will especially focus on how Lévinas seems to move in new directions concerning the material ground of the image in resemblance and the temporal fixity or congealment of the image which resemblance, as the very structure of the sensible itself, entails.

Nevertheless, despite whatever similarities or differences I may be able to demonstrate concerning Lévinas' and Sartre's accounts of the image, the key question throughout

${ }^{1}$ Lévinas, E. Time and the Other. R. Cohen, trans. Pittsburgh, Duquesne, 1987. 62. 
this paper will remain the connection between the image and temporality. Indeed, this is not a self-evident supposition. Why should one think that a phenomenological analysis of the image or image-consciousness could at all aid one's understanding of temporality? My claim is that the image for Lévinas bears out a descent of consciousness into being. It is a form of transcendence in the sense of Jean Wahl's "transdescendance": a falling back into the very origin of all consciousness in a fundamental an-archic hetero-affection. This I hold to be precisely what Lévinas is after in referring to the most original sense of the present-a present for consciousness in which it is threatened to be dragged back into the anonymous materiality of being which is both its precondition and its limit, and of which there is no guarantee that it would ever escape.

\section{Uncovering the Image: In Art or Representation?}

One finds the majority of Lévinas's descriptions of the image situated within discussions of the power and significance of art. An immediate link is to be made between art and the image according to him insofar as the essence of art "lies in not understanding," that is, in an "obscurity...foreign to dialectics and the life of ideas." ${ }^{2}$ The force of the work of art consists in its opening up a distance between one's understanding and reality. For Lévinas, the image is the elementary form under which this event of distantiation from truth and reality is accomplished, and art best lets us see how the image does this. The question is to understand exactly how the image for Lévinas is this occurrence of interference and interruption in the life of consciousness, especially with respect to its temporal continuity. Yet before doing so, it would first be wise briefly to re-familiarize ourselves with the traditional conception of the image against which Lévinas is working.

This choice on Lévinas's part to situate his descriptions of the image almost solely within the context of art is noteworthy in that it marks a significant departure from traditional phenomenological discussions of the image. Such discussions, from Husserl on, had always viewed the image to be a basic phenomenon of imagination, and thus as fundamentally (and not quantitatively) distinct from perceptions. However, despite this initial, central insight that the givenness of an object in an image is essentially different from its givenness in perception, phenomenologists could not be blind to the fact that the givenness of images is always founded on a sensuous content or a sensuous material which comes to be transformed or interpreted as the image. The task then before them was to classify different types of images according to their perceptual foundedness.

In this regard, the key issue for Husserl and Sartre concerned whether or not the image, as an intuitive representation of an absent or non-existent object, could be considered to be the paradigmatic form of any irreal object-presentation, even in cases where there is no evidence of its perceptual foundedness. In other words, it was a question of still seeing the structure of the image at work in mental presentifications, Vergegenwärtigungen, where one cannot easily point to the presence of a sensuous content on which they would be founded. Husserl found that a distinction had to be drawn between acts of image-consciousness, presupposing a sensuous datum or 'stuff' in order to be effected, and acts of phantasy-presentification which have an altogether different structure.

\footnotetext{
${ }^{2}$ Lévinas, E. "Reality and its Shadow." (henceforth RS) Collected Philosophical Papers. A Lingus, trans. Dordrecht, Martinus Nijhoff, 1987. 3.
} 
Although Sartre would much later put forth an answer very different from that of Husserl's-namely that the image is the universal structure of imagination and is hardly to be distinguished from phantasy à la Husserl-he nevertheless adopts much from the definition of the image as set out by Husserl. Sartre's account of the image is chiefly to be characterized as follows: first, consciousness of the image is an act of freedom, and second, this act of freedom takes the form of an intentional relationship which constitutes and animates-or even better, conjures up-the presence of an object.

Every image is the product of a free act according to Sartre. In this spontaneous mental process of imagination, an intentional relationship is established with an object which is either absent or non-existent, experienced as a lived, intuitive, yet irreal presence of that object. This spontaneity of the image is not merely a formal condition of images. Rather, it is evinced in Sartre's phenomenological observation that every imageconsciousness is suffused with a sense of its own superfluity, of itself as utterly bereft of any necessity whatsoever.

As Sartre writes, "an imaginative consciousness...is given to itself as an imaginative consciousness, that is, as a spontaneity which produces and conserves the object in an image." 3 When one is aware of an object through an image, one cannot but be aware of the isolation in which one stands with respect to the image-object, insofar as one's consciousness is wholly responsible for the coming to presence of that object. Hence, in Sartre's view, there can be no image without consciousness. The image is truly nothing of the world and nothing to the world. It belongs and is bound to the desire of consciousness alone, enchained to the vicissitudes of its spontaneity.

Furthermore, when describing the form taken by this free act of intentionally relating to an irreal object, Sartre ascribes an activity of constitution to the image-consciousness. "The image is an act which aims at an absent or non-existent object in its corporeity, by means of a physical or mental content which is not given on its own, but only as an 'analogical representative' of the object aimed at." 4 The act of imagination is involved with whatever sensuous datum lies at hand for consciousness, such that it can bring to appear whatever object it wishes.

This sensuous datum through which the image is brought to life is called the 'material analogon.' The imaginative intention animates and aims through the sensuous stuff of the material analogon by 'irrealizing' or neutralizing it, such that the analogon comes to function as a sort of screen through which the intended object is seized. In this respect, the image-consciousness, albeit free and spontaneous, is always in need of a sensuous material analogon to give form to and by means of which it can achieve its intuitive representation.

One should note that in speaking of consciousness of the image as being in need of a material analogon as a sort of window through which it apprehends an object, it is never a question from Sartre's point of view of whether consciousness will find a suitable sensuous analogon for its imaginative intention. So radical is Sartre's conception of freedom that it is only ever a question of how that intention will realize its aim. From Sartre's perspective, practically anything drawn from the perceptual realm can serve as an analogon for an imaginative intention, keeping in mind that some perceptual contents are better suited for this than others.

\footnotetext{
${ }^{3}$ Sartre, J.-P. The Psychology of Imagination. (henceforth IM) B. Frechtman, trans. London, Routledge, 1948. 14 (translation changed).

${ }^{4}$ IM, 20 (translation changed).
} 
Nevertheless, Sartre does speak of a certain appeal or entreaty on the part of some kinds of analogons, such as painted canvases, which come to enchant or bewitch consciousness into transforming them into an image. That is, the painting ceases to be a perceptual thing and becomes possessed by an imaginary presence, that is, the irreal object. In this connection, Sartre refers to the magical character of images, insofar as through them there is an incantation of the presence of an irreal object which consciousness seems almost not to be able to resist.

In contrast then to this 'traditional' representational-phenomenological account of the image, what are the consequences of Lévinas's situating the image within the realm and function of art? For Sartre, the question of art and aesthetics was only ever a related yet ancillary issue for a phenomenology of images. According to Lévinas, on the other hand, the essence of the image has everything to do with art. This claim announces Lévinas's own way of dealing with a basic and elementary issue with which both Sartre and Husserl had wrestled. Namely, what is it that distinguishes an image from a perception?

By still holding to this distinction, Lévinas is very much in keeping with the phenomenological tradition which preceded him. Reflection shows that the essential difference between perception and the image cannot be explained away with simplistic answers. As he puts it, "the disincarnation of reality by an image is not equivalent to a simple diminution by degree." 5 Making the connection to certain forms of art, as opposed to situating the image within the framework of imagination, allows Lévinas to place radical emphasis on passivity and affectivity as essentially defining for the image. However, before going further into those issues, let us first be clear: what does Lévinas mean by art?

A basic claim of Lévinas's, very indicative of his perspective, is that when encountering a work of art, one should never estimate it according to its expressiveness. We cannot contemplate a work of art with a view toward the success with which it is imbued with meaning. The artwork is never a form of communication, as if one should search for what the artist had tried to realize within it. Indeed, the coming about of the artwork has the sense of something aleatory, through its confronting the artist's creative intention with a stolid indifference. The painting is an event which belongs to no causality or process. He explains: "The artist stops because the work refuses to accept anything more, appears saturated. The work is completed in spite of the social or material causes that interrupt it. It does not give itself out as the beginning of a dialogue." 6 In other words, the deft stroke of the artist loads the painting not with meaning, but with sensation.

The work of art's lack of expressiveness means it has nothing to do with a creation or a revelation in the sense of a grandiose insight into being. In short, the work of art is opposed to the work of truth. It can be helpful by way of a comparison to think of Proust here as a counterpoint to Lévinas on the significance of art. For Proust, the quest for truth is not only aided by, but is realized in art. Art for him works as a clarification without which the truth of existence and experience could not be seen. ${ }^{7}$ Against this, Lévinas claims that the "inhumanity and inversion of art" manifests a reality which is unstable and which does not yield itself to any form of truth.

As a result of this original proscription of communication from the realm of art, Lévinas provides an altogether different account of the aesthetic impressions whose source is

${ }^{5} R S, 5$.

${ }^{6} R S, 2$.

${ }^{7}$ Breeur, R. "Proust." Companion to French Thought. (to be published). 
the work of art. Though art is not expressive, this is not to say that art has no interaction with us whatsoever. To the contrary, Lévinas refers again and again to the way the work of art affects us through its passivity. The 'work' of a work of art occurs under the form of an affective imposition out of which the aesthetic impression arises. Hence a further consequence of Lévinas's insisting on the close bond between art and the image: he will seek to account for this certain aesthetic affectivity as being integral to every form of the image.

Just as one example of this imposition by the artwork, take Lévinas's discussion of the photograph in Existence and Existents. Facing the photograph, the subject cannot but succumb to what the photograph shows, or more precisely, to what the photograph prevents from being shown. It is clear that in this way Lévinas would play down the role of freedom in the work of art. Yet more importantly still, Lévinas speaks of a transformation of the subject, an essential "modification of contemplation itself." 8 The subject is transformed when the work of art "interposes an image of the thing between ourselves and the thing." The imposition is thus this interfering presence of the image to which the subject must yield. And this interposition of the image between ourselves and the thing in the photograph results in our being deracinated from the "perspective of the world."

The 'world' here can basically be taken to mean the totality of our perceptual relations with things. In perception, "sounds, colors, words refer to the object which they as it were cover." 10 Sensible impressions of qualities, such as sounds or colors, are always referred to objects. By being so bound to objects, these qualities are always constituted. They are always given a form according to the object from which they are inseparable. Such would be the realm, for example, to which Sartre's pour-soi would seem to be condemned for most of its existence, where there is no blue without a sky, no drear without a cloud. This adherence of sensible impressions to forms means that woven between them all is an infinite yet stable chain of references. A perceptual object with its sensible qualities is but a form set on the background of yet another form, on to infinity. This network of forms is the world.

The work of art brings about our extraction or deracination from this world by introducing an image between ourselves and the thing. The image does not serve as a conduit for apprehending some thing. The chiaroscuro in the photograph which catches our attention does not at all draw the thing closer to us. Rather, it presents the thing as though it were removed at an infinite distance, in so doing obscuring it and pulling it out of the world. Through the work of art, then, one is related to a presence which is no longer of the world. Thus we should not think of the work of art as ever granting an ingress to another fey world, whose portal is somehow nestled within our perceptual world. The image working through the work of art marks the very collapse of the world into the sheer presence of the image-thing.

How does this implosion of the world in the image signify the transformation of the subject through the work of art? For Lévinas there can only be a subject which is in and related to the world. As he writes of consciousness in a note to another early text from 1940 , critiquing Sartre at the same time, "in the movement of the intention toward the outside, there is no flight from self, no predilection for the outside because it is

\footnotetext{
${ }^{8}$ Lévinas, E. Existence and Existents. (henceforth EE) A. Lingus, trans. Dordrecht, Kluwer, 1978. 52 (translation changed).

${ }^{9} E E, 52$.

10 EE, 53.
} 
outside." ${ }^{11}$ Quite simply, according to Lévinas there is no subjectivity, no consciousness, without the 'outside' of objectivity, the world. Consciousness, in its intentionality, is outside, and by being outside, in the world, it can have an inside, what we hold to be its subjectivity, that of perceptions, meanings, feelings, etc.

Thus, if the work of art confronts one with the presence of a thing which has been infinitely withdrawn from the world, then consciousness itself must also undergo a radical change. In short, due to the image, one can no longer speak of a 'subject' for the work of art. Very much in contrast to Sartre, for whom the image is one of the exemplary forms under which the subjectivity of the subject is revealed as one's own condemnation to an insouciant and capricious freedom, for Lévinas it is improper to construe the work of art as revealing the subjectivity of the subject. One should rather try to understand it as a 'de-subjectification' of the subject; an uprooting of the subject from its subjectivity by tearing it out of its stable world. Yet this uprooting through the work of art occurs without replacing subjectivity with any new form of being. The implosion of the world in the work of art coincides with the explosion of subjectivity.

This implosion/explosion of the world/the subject will become much clearer in looking at how for Lévinas the elemental materiality of sensation reveals in the image a dimension of being beyond all subjectivity and objectivity, or as he also puts it, beyond any "exteriority or interiority". This preclusion of any polarity establishes the "distance," referred to earlier, of the thing depicted in the image. It is a distance which can neither be traversed nor overcome.

\section{The Amphiboly of the Image: Between Representation and Sensibility}

Thusfar, the discussion has been limited to Lévinas's privileging of art as the locus naturalis of the image. We have defined the work of art as an interposition of an image between oneself and a thing, and have referred to some of the effects which this interference of the image comes to have through the work of art. The image is the inner structure of the work of art for Lévinas. That much is clear. Yet exactly how does the image bring about that which Lévinas attributes to it?

The solution lies in what I would like to call the 'amphiboly' of the image. The choice of this term comes out of the fact that in Lévinas's descriptions, one finds no less than two very different sorts of descriptions of the image. The first can be termed the image in its representational attributes. The second, on the other hand, are Lévinas's descriptions of the image in its a-representational or anti-representational characteristics.

The amphiboly of the image simply means the image has this ambiguous and dichotomous structure. The image would seem to move in two directions at once for Lévinas; toward representation and at the same time toward its decomposition and renunciation in the raw or nude materiality of sensation. The amphiboly of the image also entails that while each of these two 'movements' or 'tendencies' intrinsically need each other, draw off each other in the image, there is never any resolution or conquest in their conflict. The death of representation in the image is always on the cusp of occurring once and for all, while its possibility is constantly being renewed in the image's striving to present oneself with an object. Let us then delve into how Lévinas explicitly presents these two tendencies as the inner workings of the image.

\footnotetext{
${ }^{11}$ Lévinas, E. "The Work of Edmund Husserl." Discovering Existence with Husserl. R. Cohen and M. Smith, trans. Evanston, Northwestern, 1998. 188 (note 112).
} 
(a) The necessity of resemblance

First, what are the representational attributes ascribed to the image by Lévinas? With respect to their composition, Lévinas refers to a law or rule belonging to images, inherent in their nature, from which they cannot deviate. Lévinas addresses this necessity in the nature of images in different ways. For instance, he writes of the way the image "must reproduce the real situation or event." 12 Or, in reference to Eugen Fink's famous essay on images and phantasy, ${ }^{13}$ he concurs that "the intention is indeed directed to the tree itself across the perception of the painted tree, and we thereby enter the world of the painting, which is different from the real world." ${ }^{14}$

Lévinas does not deny that the nature of the image is to direct our attention to some or other object, in one or another fashion. Despite everything else one might say about his account, the image for Lévinas remains a form of givenness, occurring in the particular way it refers to an object. Moreover, according to Lévinas, the better this reference is accomplished, or in other words, the more the image simulates a irreal world, the more image-object remains tied to and belongs to this world, rather than being torn from it. ${ }^{15}$ And in such cases the image would fail to extract the subject from the world.

Hence cinema and television in Lévinas's account are intriguing instances where the amphiboly of the image is nearly eradicated, because due to their success of representation it is more difficult for our links to the world to be broken. It would be valid to think of a hierarchy of images for Lévinas, according to the ambiguity of representation which they disclose. In this way, one might explain his apparent reluctance to say much about imagination in contrast to perception, while still holding to the unique status of the image, according to this view that certain images more than others may fail to extract the self from the world.

The necessary reference of an image to an object comes from the very foundation of the image, in resemblance. What is the source of this necessity, this law of representation which is convoked in the image? By way of a comparison, in Sartre's phenomenological account, one could be tempted to speak of consciousness as always 'driven' to have objects before itself. Consciousness is an unfailing synthesis of the elemental stuff of being into objects. Accordingly, there is a blindness to all but objects for Sartre's poursoi. Thus, while Sartre would never have said that consciousness creates the world and objectivity as if it were its dream, there is a very strong sense in his philosophy of consciousness as shaping, constituting the world, meaning that it gives itself objects at least as much as they are given to it. Hence the pour-soi for Sartre being one of two fundamental and primordial ontological categories.

On the point of resemblance then, Sartre's position is clear. Sartre writes that it is the "internal relationship" between the object and the image, or more precisely, its "material analogon.' Resemblance in the analogon is the "expressive tendency" of the sensible material, as if it almost, but not quite, had a force upon me. "The painting gently begs me to look upon as a man." ${ }^{16}$ Nonetheless, it is consciousness' desperate clinging to objects which shapes that material into the image.

${ }^{12} E E, 52$.

${ }^{13}$ Cf. Fink, E. "Vergegenwärtigung und Bild: Beiträge zur Phänomenologie der Unwirklichkeit" (1930). Studien zur Phänomenologie, 1930-1939. The Hague, 1966.

${ }^{14} E E, 54$.

15 “....an art work as a whole expresses what we call the world of the artist... Through sympathy for this soul of things or of the artist the exoticism of the work is integrated into our world." $E E, 55$.

${ }^{16} I M, 23$. 
For Lévinas, this "expressive tendency" in the image, not of a meaning, but of a mirroring, an imitation, a reproduction, largely holds true, but in his philosophy it takes on a completely different ontological significance. This is to such an extent that one can get the impression that images are independent of and pre-exist consciousness for Lévinas. Resemblance is not a matter of what consciousness finds in a sensuous content. It pre-dates consciousness, and allows for there to be such a thing as an image. Thus for Lévinas, as opposed to Sartre, there are, as it were, 'lower levels' of being to be delved into, outside of objectivity, at the very limits of consciousness, out of which the dictate of representation in the image arises.

It is at this lower, more primordial level of being that resemblance occurs. Resemblance, as Lévinas explains, is not an inter-relationship between an image and its object to be established by thought. Resemblance is neither the product of a reflection nor a recognition. Rather, resemblance founds the instantaneous leap into the image on which Sartre, for example, greatly insists. In the image, there is a withdrawing of the original from itself, in delaying, lagging behind, interfering with itself, and this withdrawing is "the very movement that engenders the image." Lévinas continues: "Reality would not be only what it is, what it is disclosed to be in truth, but would also be its double, its shadow, its image."17

This non-self-coincidence is the structure of all sensible reality for Lévinas. Reality coinciding with itself would be objectivity, substance, shape and solidity, hence the reality of forms, of truth. Yet underlying this reality is the reality of the sensible, which in its constant resembling and duplicating of the reality of truth, i.e. the world in which we live, resists all form and stasis. Notice here that both realities, the reality of truth and its shadow, are fundamentally tied together. Lévinas reminds us that we should not "fail to recognize the simultaneity of truth and image" which is the event of resemblance.

Finally then, how does the image function according to resemblance? Lévinas clarifies this in the following passage:

The consciousness of representation lies in knowing that the object is not there. The perceived elements [the 'material analogon' (B.V.)] are not the object but are like its "old garments," spots of color, chunks of marble or bronze. These elements do not serve as symbols, and in the absence of the object, they do not force its presence, but by their presence insist on its absence. They occupy its place fully to mark its removal, as though the represented object died, were degraded, were disincarnated in its own reflection. The painting does not then lead us beyond the given reality, but somehow to the hither side of it. ${ }^{18}$

The play of absence and presence is unmistakable in this passage. The representation of the object through the image is the synthesis of absence out of presence, and out of that absence, one would aim at yet another sheer presence-the image-object. The presence of the "perceived elements" in the painting are traces of the object itself, its being in pre-human sensation. These traces come not from consciousness, but are 'events' of self-mimicing and reproduction initiated by the sensible reality itself of the object. These presences, strewn about within the painting like "old garments," are reverberations, resonances of reality with itself, which are then caught up in the image of the object as ineluctable dispersions of its ground in sensibility.

(b) The image as anti-representation: the anarchy of the sensible

\footnotetext{
${ }^{17} R S, 6$.

${ }^{18} R S, 7$. (my emphasis)
} 
Yet according to Lévinas, just as much as these presences in the image would present the object in its absence, they simultaneously obscure it and mislead one's attention. In this obscuring, one gets drawn further and further into the materiality of sensation itself, out of which that 'indicative' presence of resemblance is composed. "A represented object, by simple fact of its becoming an image, is converted into a nonobject." ${ }^{19}$ Lévinas further specifies that the image "consists in leaving the level of perception so as to reinstate sensation, in detaching the quality from the object reference." ${ }^{20}$ In the image, therefore, concomitant with the movement toward representation, sensation itself appears. "Instead of arriving at the object, the intention gets lost in the sensation itself... Sensation is not the way that leads to an object, but the obstacle that keeps one from it." 21

The sensation appearing in the image obscures the image-object and destroys representation because through the image, it is revealed as opposed to objectivity. Lévinas likens the sensations in images to sounds, musicality, rhythm-all these being experiences where one is in the presence of something which cannot be held onto and which thus seem to defy objectivity. The musicality of sound (and this holds for every sound according to Lévinas) is its refusal to be attached to any object or to any "category of substance." Self-attachment would be the very definition of substance for Lévinas. By contrast, in the musicality of sound, there is a temporal renewal and a withdrawal which mocks any consciousness which would attempt to seize and fastidiously hold onto the sensuous material of the sound, as if to apprehend it once and for all as a static presence. For Lévinas, just as with the musicality of every sound, the sensations in images continually echo themselves, reminding us of their insubstantiality, and refuse to persist as objects.

This rebelliousness and playfulness of sensations is what Lévinas calls the "anarchy of the sensible." 22 It denotes the fact that in the painting, the photograph, or the cinema close-up, there are always elements which refuse to 'fit' into the whole, the totality, of the representation, into its form as an object. These sensations refuse to contribute to a substantialization of the object through the image. Yet not only do they refuse to play along, to 'make up' its presence. At the same time, they haunt and threaten, detract from the very possibility of a synthesis of representation. They infiltrate its unity and draw the intention of the viewer away from the form, 'down into' the nude materiality of the painting itself.

Any color or sound (and even words!) can come to play this anarchic role in images, because as sensations they are susceptible to their own rhythm and musicality, as Lévinas says. Due to the materiality of their basis in the image, they can at any moment become detached from any order of objectivity and meaning, turning into "naked elements, simple and absolute, swellings or abscesses of being," ${ }^{23}$ breaking with the bonds by which being becomes self-absorbed in our perceptual world.

To exemplify the "anarchy of the sensible" further, Lévinas speaks in praise of the coeval abstract painting of his day in its "protest against realism" and "destruction of representation." These kinds of painting surrender any fascination with objects, and exist as "fissures" in the order of the universe, letting the things themselves, the sensations, appear for themselves. For Sartre, such kinds of painting, in which a sensible richness confronts one, may well be enjoyable, but have little to do with either

${ }^{19} R S, 5$.
${ }^{20} E E, 53$.
${ }^{21} E E, 53$.
${ }^{22} E E, 53$.
${ }^{23} E E, 56$. 
the image or the aesthetic. He writes that when one is before such a painting, "this sensuous enjoyment, if thought of in isolation,...is purely and simply a pleasure of sense. But when the red of the painting is grasped, it is grasped, in spite of everything, as part of an unreal whole and it is in this whole that it is beautiful."24 The voluptuous red in Matisse's painting is only either of the painting or of the imaginary object. When we would be aware of such sensations "in isolation" in the painting, we would simply be enjoying an impression in the realm of perception, and only by contributing to the formation of irreal representations of objects do such impressions play a role in the imaginary for Sartre. For Lévinas, on the other hand, such raw sensations have nothing to do with perception, but utterly permeate every consciousness of the image. In his account, it is as if it were the 'material analogon' itself (to use Sartre's term) which rises up before one in the image, resisting its integration and synthesis into the imaginary representation.

\section{The Instant in the Image}

In describing the "amphiboly of the image in this manner, we have tried to address the different ways in which Lévinas investigates the "essential distance and obscurity" at work in the image. Yet, having seen these two conflicting movements in the image, we are now in a position to understand what Lévinas holds to be the most significant aspect of the image, namely its radical affection of our temporality. For Lévinas, the image signifies the manifestation of the pure instant, as the interruption of the continuity of life. In the image, we realize that time can stop. ${ }^{25}$ The image is "in the end a statue - a stoppage of time, or rather its delay behind itself." 26

This insight comes out of an intriguing yet difficult question which both Lévinas and Sartre raise: namely, what is the temporality of the image? In other words, can the essential distinction between the image and a perception also be approached with respect to two different sorts of temporality? Lévinas and Sartre would both respond affirmatively to this.

Sartre, in his analysis of the image in The Psychology of Imagination, describes the temporal isolation of the image, which could also be called its congealment or fixity. At first, this attribute seems merely to come out of the phenomenological observation that there is no development in the image. But one has to go further than this. When I perceive a rock, is that not also a valid recognition-that I perceive no development in the rock? What is the difference then between the 'life' of a real perception of a rock, and the 'fixity' of the image of the rock. In short, what is the instant in the image?

To understand this, the continuous, perceptual experience of duration has to be contrasted with its isolation and discontinuity in images. First of all, with duration, what endures? Both consciousness and objects can be described as having a duration. Sartre maintains that these two kinds of duration are distinct. The duration of objects cannot be confused with the flow of time, the flux of moments ecstatically related, through protention and retention, by which consciousness unifies itself. The duration pertaining to the appearance or continuity of appearance of an object, differs "in nature" from the manner in which one has self-awareness of a flow of consciousness as lasting through time. ${ }^{27}$ The consciousness of the temporal extension and ekstasis of consciousness

${ }^{24} I M, 221$.

${ }^{25} R S, 11$.

${ }^{26} R S, 8$.

${ }^{27}$ IM, 147. 
itself, is completely different from any other way that one experiences time, as something happening in or to the world and its objects.

The duration of objects for Sartre describes a simple experience-the way an object merely lasts before a perception. I stare at a rock. I am aware of having it as my object for a time, in its continuous passing into the past and its entrance into the future. This means, on the one hand, that in my perception, I am implicitly aware of 'my' time, as the temporal flow of consciousness from moment to moment. It also means that at the same time, I am aware of the time taken up by the rock through my perception. The latter aspect of an experience of time, attributed to an object, is nothing else than the object's duration-the segment of time in which the rock 'lasts' as the perceptual object. What distinguishes it from the former sense is that this duration is enmeshed with the object of consciousness. Time is inseparably interwoven into the enduring object as the richness of its appearance.

With images, on the contrary, one has no true experience of their duration. The image remains "invariable" due to its amphiboly, the conflict of representation and sensation, or in Sartre's terms, the conflict between poverty and observation. ${ }^{28}$ The image is thus "without time." 29 It does not last before consciousness in the way that a perceptual object does. Its existence is wholly reliant on each passing moment of the intention searching throughout the image for its object, and nothing of it carries over from moment to moment. Unlike the rock I perceive, the image has no invisible sides, against which one could contrast the appearing in this present of its aspect. The image has nothing else of itself to stand out from, as varying from its other appearances or determinations. Thus, I cannot at all be aware of the 'time' that an irreal object 'takes up' in my consciousness, as I might be able to in front of a real object to some greater or lesser extent. When I snap out of a daydream, what first strikes me is a certain disorientation as to how long I have been 'gone' for, from the 'time' of this perceptual world.

In "Reality and Its Shadow," Lévinas draws much the same sorts of conclusions in discussing "the meanwhile" or the instant into which the image is cast, but explains that this is not due to a poverty of sensation in the image, but is due to a certain richness and exuberance of sensations in images. One is left with only traces of the forms of objects in overwhelming sensations, which because of their anarchy just as much detract from the representation as contribute to it. The intention exploring the image is therefore caught, trapped, suspended in this irresolute instant, in being faced with a presence which endures with neither a future nor a past. ${ }^{30}$ The instant is a moment which does not pass, which has no reference to a past or a future. It is the meanwhile, the present which is bound to a sheer presence and from which consciousness cannot escape. In the image, because of its irresolution between representation and sensation, the continuity of time dies.

There is yet another crucial difference. For Sartre, the temporal isolation of the instant occasions a failure of the desire of consciousness. This is brought about by the poverty of the image which consciousness constitutes in its desire for being-this poverty throws desire back on itself and signifies the arrest of desire, desire realizing itself, confronting itself with nowhere else to go, nothing else to strive for. However, Sartre's pour-soi is incessant in its desire, which means that while the image may be halted and gelid in its 'a-temporality,' the temporality of consciousness itself goes on. Its fascination with and desire for being remains unvanquished. By contrast, Lévinas

${ }^{28} I M, 147$.

${ }^{29} I M, 147$.

${ }^{30} R S, 9$. 
advances a much more radical view, according to which Sartre's precious distinction between the temporality of consciousness and that of the image dissolves. Pointing to the instant in the image, Lévinas questions the preponderance of the Bergsonian notion of continuity as "the very essence of duration." ${ }^{11}$ Yet according to him, it is not only the continuity of the existence of an irreal object or the world which is threatened in the image. The image marks an assault on the continuity of consciousness itself.

The instant of the image signals an interruption in the temporal continuity of life itself, and not just in the irreal realm of the image object, due to the fact that in front of an image such as a painting one does not face a choice between either perceiving its perceptual elements or seizing its imaginary object, as Sartre would have it. Instead, as Lévinas puts it, in the image one risks being caught up in the phenomenon of "transdescendance." ${ }^{2}$ In this Lévinasian phenomenon of "degradation," the emergence of the raw sensations, the "naked elements" fetters consciousness from going on in its intentionality, due to their conflict with representation which has been described as the amphiboly of the image. Yet in this manacling of consciousness, these raw sensations, as the pre-conditions for presence of being in the image, are therefore revealed as the "pre-human" pre-conditions for one's being, i.e. the present of the temporality of consciousness, its presence to being.

\section{Conclusion}

To draw a conclusion about Lévinas's and Sartre's different 'images' of time, it is necessary to say something about the meaning of the present for Sartre. In one sense, the present is that to which the pour-soi is interminably condemned, insofar as the pour-soi is defined for Sartre by its inescapable presence to the world. Yet in another sense, the present is that which the pour-soi constantly gives to itself, insofar as the nature of the pour-soi is always to transcend itself toward what it is not, namely the world and its own future. ${ }^{33}$ Thus, the present of temporal life always has for Sartre the sense of a release and an emancipation from the past and the present, since its incessant self-transcendence precludes that it would ever coincide with its presence to the world, and thus be its own present. And thus, while the image for Sartre may indeed be about a loss of duration, this interruption in no way affects consciousness itself, in its self-pursuit and self-flight which constitutes its temporality. The image in no way would ever bring consciousness to question the givenness of its future.

With Lévinas, on the other hand, we have quite a different situation. The image, as we have seen, leads to an "interruption of time by a movement going on on the hither side of time, in its 'interstices," ${ }^{34}$ as a result of what I have tried to explain as its amphiboly of representation and anarchic sensation. This interruption is carried out, not just for the world, but also in the subject's own time, and entails their implosion/explosion referred to earlier. Hence, the image is intimately linked to the issues of the future and death for Lévinas. The image returns us to the materiality of the sensible, and reminds us of the very instability of the continuity of time, where the future is never certain, and is never self-given, but can only arise out our affection by the new, by our affection by an otherness. Our death is when a future is no longer given, when we are no longer

\footnotetext{
${ }^{31} R S, 11$.

${ }^{32} R S, 8$.

33 "(The pour-soi as presence to...) is the wrenching away from self within the unity of a single upsurge, an inapprehensible totality which at the moment when it gives itself is already beyond this gift of self." Sartre, J-.P. Being and Nothingness. H. Barnes, trans. London, Routledge, 1943. 149.

${ }^{34} R S, 3$.
} 
affected by the future, when we are caught in a conflict of anticipating a future without its being given. Thus Lévinas likens the interrupted temporality of the image, that being our own stoppage in the instant, to the "time of dying," in which "the instant cannot come to pass...in dying, the horizon of the future is given, but the future as a promise of a new present is refused; one is in the interval, forever an interval."

${ }^{35} R S, 11$. 